\title{
A pesquisa da prática pedagógica em aulas de ciências por bolsistas do PIBID
}

Research on pedagogical practice in science classes by PIBID fellows

\author{
Andrela Garibaldi Loureiro Parente ${ }^{1}$ \\ José Moysés Alves
}

\section{Resumo}

Neste estudo abordamos as contribuições do tema Linguagem e Conhecimento $\mathrm{V}$ para a formação inicial de professores dos anos iniciais, apoiados em discussões sobre prática pedagógica, aprendizagem em ciências e professor pesquisador. A professora formadora e os licenciandos, bolsistas do PIBID, em uma perspectiva de pesquisa ação colaborativa, planejaram e realizaram aulas de ciências, sobre temas relevantes. Refletiram sobre essas aulas, analisando a comunicação dos bolsistas com os estudantes. Os licenciandos também produziram relatos pessoais e biografias educativas. Analisamos esse material, interpretativamente, para compreender o processo formativo, apontando as mudanças, avanços e projeções realizadas pelos bolsistas. Além de relacionarem teoria e prática, os licenciandos refletiram sobre a aprendizagem dos estudantes e suas formas de atuação nas aulas realizadas. Também refletiram sobre suas trajetórias de formação e desenvolveram novos interesses relacionados à teoria e à prática pedagógica.

Palavras chave: Formação inicial; Aulas de ciências; Pesquisa da prática; PIBID.

\section{Abstract}

The research addresses the contributions of the theme Language and Knowledge $V$ to the initial training of teachers for the early years. It is based on discussions about pedagogical practice, science learning and the researcher teacher. The professor and undergraduate students, PIBID fellows, in a collaborative action research perspective, planned and held science classes on relevant topics. They reflected on these classes, analyzing the fellows' communication with students. Undergraduate students also produced personal reports and educational biographies. We analyze this material, interpretively, to understand the training process, pointing out the changes, advances and projections made by the fellows. In addition to relating theory and practice, the undergraduates reflected on the students' learning and their ways of acting in the classes held. They also reflected on their training trajectories and developed new interests related to theory and pedagogical practice.

Keywords: Initial training; Science classes; Research on practice; PIBID.

\footnotetext{
${ }^{1}$ Universidade Federal do Pará | andrela@ufpa.br

${ }^{2}$ Universidade Federal do Pará | jmalves@ufpa.br
} 


\section{Pesquisa da prática na formação inicial de professores}

A prática pedagógica é uma atividade complexa. As dimensões formativa, relacional, pedagógica e profissional coexistem, configurando relações específicas na ação de ensinar (ALTET, 2017). Tais relações estão presentes no processo de formação, intencionalmente orientado para a aprendizagem, e se contrapõem a crença de que para ensinar, basta dominar conteúdos e algumas metodologias de ensino. Nesta perspectiva, na pesquisa que relatamos a seguir, objetivamos investigar as contribuições do tema Linguagem e Conhecimento V (LC V) do curso de Licenciatura Integrada em Ciências, Matemática e Linguagens (LIECML) para a formação inicial de licenciandos, bolsistas do Programa Institucional de Bolsas de Iniciação à Docência (PIBID).

O curso da LIECML visa formar professores para atuar nos anos inicias, valorizando a educação em ciências e matemática integrada à língua portuguesa e aos estudos sociais. Somos professores do curso e compartilhamos discussões e reflexões sobre a formação inicial em Linguagem e Conhecimento, um dos temas que fazem parte dos componentes curriculares da formação profissional. Ao longo de sua trajetória de formação, o licenciando cursa o tema, amplia e aprofunda essa discussão, estudando assuntos novos, entre outros, explorando a especificidade da comunicação em aulas de língua portuguesa, matemática e ciências.

Consideramos importante realizar pesquisas sobre nossas práticas de formação inicial de professores para os anos inicias (ALVES; PARENTE, 2020). No âmbito do tema LC V, em particular, temos buscado avaliar de que modo a investigação dos licenciandos sobre suas práticas de ensino, especificamente, sobre a comunicação em suas aulas de ciências, pode favorecer princípios formativos previstos no Projeto Pedagógico da LIEMCL, tais como autonomia, criatividade, parceria e sensibilidade.

\section{Por que é importante estudar a comunicação em aulas de ciências?}

Práticas pedagógicas que incentivam e valorizam a comunicação em aula se opõem à visão de ensino que prioriza a memorização (ASTOLFl; PETERFALVI; VÉRIN, 1998). A orientação teórica de tais práticas enfatiza o processo comunicativo entre professores e estudantes, pois entende que nele são disponibilizadas ferramentas simbólicas imprescindíveis para o desenvolvimento do pensamento, além do compartilhamento de significados produzidos culturalmente.

Altet (2017) defende a compreensão complexa do funcionamento das práticas pedagógicas. Nesta visão, inclui o professor, o estudante e a situação, bem como as diferentes relações originadas na dinâmica das interações que se efetivam em aula. De acordo com a autora, as práticas pedagógicas evoluíram e colocaram o estudante no centro do processo. Assim, uma concepção de aprendizagem torna-se necessária, já que para ensinar é fundamental o professor saber como os estudantes aprendem.

$\mathrm{Na}$ área de Educação em Ciências, a aprendizagem como enculturação científica privilegiou a produção de significados no processo comunicativo, valorizou o diálogo em aula, tendo como referência o discurso da comunidade científica (CACHAPUZ; PRAIA; JORGE, 2004). Essa concepção de aprendizagem se opôs à visão empirista de produção de conhecimento científico, criticou a concepção de aprendizagem como mudança conceitual e defendeu a natureza simbólica e socialmente negociada do conhecimento científico. Deste modo, 
As entidades e ideias científicas, que são construídas, validadas e comunicadas através das instituições culturais da ciência, dificilmente serão descobertas pelos indivíduos por meio de sua própria investigação empírica; aprender ciências, portanto, envolve ser iniciado nas ideias e práticas da comunidade científica e tornar essas ideias e práticas significativas no nível individual (DRIVER, et al., 1999, p. 32-33).

A aprendizagem como enculturação científica foi um avanço dentro da área de Educação em Ciências, pois teorizou sobre um conceito de aprendizagem, afastando-se do empirismo ingênuo. Fundamentou-se em estudos produzidos no campo da didática das ciências e na compreensão histórico-cultural do desenvolvimento humano formulada por Vygotsky (1984; 1987).

A Teoria da Subjetividade, desdobramento atual das ideias de Vygotsky, defende uma nova concepção de aprendizagem (MITJÁNS MARTINEZ; GONZÁLEZ REY, 2017). Ao considerarmos a aprendizagem nesta perspectiva, a discussão sobre as práticas pedagógicas e o estudo da comunicação em aulas se ampliam pela integração simultânea da dimensão simbólico e emocional na análise dos processos educativos.

Ao se afastar da ideia de aprendizagem como reprodução e valorizar as produções simbólico-emocionais do sujeito, a teoria da subjetividade compreende que a imaginação e a criatividade assumem papel relevante na produção do conhecimento. De acordo com a Teoria da Subjetividade "o sujeito é gerador, ativo e produtor de realidade" (GONZÁLEZ REY, 2014, p.37).

Nesse sentido, o homem é um ser social, mas sua subjetividade não é a cópia de uma realidade externa a ele. Portanto, a aprendizagem não é resultante de uma relação direta com o que é ensinado, mas do sentido que o sujeito produz ao se relacionar com novas experiências. Deste modo, o clima criado na interação entre os participantes e o apoio oferecido são fundamentais para a efetividade da aprendizagem e desenvolvimento do sujeito (TACCA, 2008; MITJÁNS MARTINEZ; GONZÁLEZ REY, 2017).

Do ponto de vista da Teoria da Subjetividade, a comunicação é um processo dialógico e relacional e serve à construção de relações afetivas que criam condições para os sujeitos se expressarem, tornando possível acessar suas motivações, bem como gerar saberes que permitem reposicionar o estudante no seu processo de aprendizagem. Deste modo, no processo comunicativo o professor interpreta os interesses e os impasses, as dificuldades que se impõem no conjunto de manifestações individuais, proporcionando debates que possam contribuir com novas produções subjetivas, ou seja, com a aprendizagem e desenvolvimento dos estudantes (TACCA, 2008).

No contexto efetivo das práticas pedagógicas, as representações que o professor possui sobre como ocorre a aprendizagem, muitas vezes, não é consciente. Entre outros aspectos, o estudo da comunicação permite investigar as condições em que se desenvolve o ensino e as representações que o professor faz de como os estudantes aprendem. Por exemplo, o ensino que valoriza a construção empírica dos saberes, concebe a aprendizagem como um processo progressivo em que as noções são postas de forma intuitiva, ou seja, entendendo que o estudante "deve olhar, raciocinar e concluir, adquirindo assim os seus conhecimentos, da mesma maneira que os saberes científicos se construíram, lenta e silenciosamente, a partir dos dados" (ASTOLFI; PETERFALVI; VÉRIN, 1998, p.38). 
A comunicação assume um caráter complexo pela existência de numerosos discursos e pelo estatuto privilegiado que um deles assume nas observações e intervenções do professor, ao conduzir e dar novos prosseguimentos em aula. No processo comunicativo, interesses e perspectivas diferentes se encontram, produzindo interlocuções que se aproximam ou se afastam das intencionalidades educativas. Se a atenção está voltada para a aprendizagem dos estudantes, as interlocuções representam desafios para os professores criarem estratégias pedagógicas que impactem positivamente nesse processo, o que lhes exige capacidade criativa (TACCA, 2008).

Deste modo, o estudo da comunicação em aula permite compreender o ensino e as condições de aprendizagem geradas na interação com os estudantes, fornecendo informações que permitem discutir e tecer uma interpretação sobre este fenômeno, bem como indicar caminhos alternativos e melhorias. Nesta pesquisa, o estudo empírico da comunicação em aulas de ciências implicou, para os licenciandos bolsistas do PIBID em formação inicial, assumir uma compreensão de aprendizagem, buscar realizar ações coerentes, relacionando teoria e prática no ensino, com o intuito de gerar condições favoráveis à aprendizagem dos estudantes dos anos iniciais.

\section{Por que é importante realizar pesquisa da prática pedagógica?}

Sthenhouse (1987) propôs a ideia de professor pesquisador e defendeu que são os professores que atuam nas escolas, em colaboração com pesquisadores mais experientes, que têm condições de propor, realizar, analisar e avaliar alternativas para o aprimoramento do processo de aprendizagem dos estudantes. O autor criticou e apontou limites aos estudos que usam o espaço de sala de aula para produzir informações e, posteriormente, oferecem soluções técnicas à ação do professor, desconsiderando sua autonomia. Para ele, o ensino era uma arte e o pensamento criativo uma condição de atuação profissional, tão importante quanto a sensibilidade, o conhecimento, a capacidade de reflexão e a dedicação profissional.

André (2016) explicita condições fundamentais para o professor tornar-se professor pesquisador e adverte para a importância de diferenciar a ação de ensinar da ação de pesquisar, embora considere a possibilidade de articulação entre elas. A pesquisa do professor pesquisador se configura a partir de um problema e no contexto de uma discussão teórica. Ao mesmo tempo, orienta a ação do professor pesquisador para a produção de informações e para a construção analítica do estudo, exigindo dele avanços em relação à compreensão do fenômeno estudado. Considera que o ensino é complexo e que a pesquisa é analítica, rigorosa e sistemática, sendo o seu propósito gerar inteligibilidade sobre algo desconhecido da prática social.

Contudo, a autora afirma que é possível ser um bom professor mesmo não fazendo pesquisa sistemática, esclarecendo que a pesquisa que se faz da prática, com a intenção de melhorar a atividade do professor, é diferente da pesquisa acadêmica, no nível de mestrado e doutorado, embora ambas sejam exigentes. Assim, argumenta que: "a academia tem um compromisso com o avanço da teoria, a pesquisa da prática volta-se para a realidade para conhecê-la melhor e modificá-la" (ANDRÉ, 2016, p.28).

Fagundes (2016) lembra que a motivação para o movimento do professor pesquisador no contexto inglês, referida por Sthenhouse, relaciona-se com a pertinência dos conteúdos escolares para a vida dos estudantes, de modo que os estudos fossem interessantes para eles. No contexto brasileiro, a origem do termo ocorreu devido à insatisfação em relação às 
teorias que subsidiavam a formação inicial. Estas não davam conta de fomentar uma prática orientada para atender às necessidades dos estudantes, oriundos de contextos socioculturais diferentes.

Ainda que existam diferentes concepções de professor pesquisador, os autores concordam que é desejável desenvolver esta noção na formação, visando a inserção ativa e comprometida de profissionais na sociedade (ANDRÉ, 2016) e a construção de modelos críticos de formação de professores (DINIZ-PEREIRA, 2011). Essa compreensão tem inspirado alguns estudos na formação inicial e continuada de professores.

A pesquisa de Emmel e Pansera-de-Araújo (2017), na formação de licenciandos em biologia, utilizando observação de aulas de ciências na educação básica e a produção de diários reflexivos, possibilitou conhecer como professores utilizam o livro didático, discutir sobre o seu predomínio nas aulas de ciências em detrimento de outros recursos, destacando o papel do professor na construção do currículo escolar.

A pesquisa de Fernandes e Miguel (2017), na formação continuada, sobre aulas de campo no ensino de ciências, permitiu que professores avaliassem a influência da diversificação de espaços e recursos de ensino na curiosidade e interesse dos estudantes em aprender. Os professores interpretaram desenhos produzidos por estudantes do primeiro ano do ensino fundamental, demonstrando a ampliação de seus repertórios sobre plantas do ecossistema Mata Atlântica.

O conceito de professor pesquisador contribui para superar a ideia comum, muito presente na formação inicial, de que para ensinar é necessário apenas o conhecimento dos conteúdos escolares e de algumas técnicas de ensino (GATTI, 2019).

O professor pesquisador da prática não trabalhada de forma isolada. Integra comunidades investigativas e contribui com o trabalho da escola. Ele concebe a formação inicial como um momento do desenvolvimento profissional, que se prolonga ao longo da vida. A realização de boas práticas não depende apenas da formação, é necessário considerar "outros fatores como o salário, a carreira, as condições de trabalho, o clima institucional, as relações de poder, as formas de organização do trabalho pedagógico que afetam o desempenho do professor. [...] há muitos fatores que concorrem para o sucesso ou o fracasso escolar" (ANDRÉ, 2016, p. 31). Para Diniz-Pereira (2011) é impossível falar de professores pesquisadores sem considerar as condições de trabalho e qualificação profissional.

Entendemos que a atividade do professor não é uma tarefa trivial e que a prática pedagógica é formativa por pressupor um campo de estudo e de geração de aprendizagem crítica da prática. Assim, a atividade do professor é relacional não somente por considerar o outro ou o trabalho coletivo, mas também devido às relações diferentes que se configuram na atividade do professor, como o clima institucional e o contexto de trabalho, produzindo condições que afetam sua ação. É pedagógica, considerando requerer criatividade do professor, exigindo dele conhecimentos para agir em circunstâncias imprevisíveis em seu trabalho e na relação com os estudantes. Também porque gera recursos pessoais imprescindíveis para o seu crescimento pessoal e coletivo, bem como a produção de recursos didáticos orientados para as necessidades de aprendizagem que identifica. A atividade do professor é profissional, porque objetiva realizar um trabalho melhor, na busca de soluções para os problemas que enfrenta no processo de aprendizagem dos estudantes, sem desconsiderar o contexto em que está inserido. 
A formação para um novo desenvolvimento profissional baseia-se na concepção de um professor pesquisador, que vai se orientar para compreender as teorias implícitas na ação, fundamentá-las, revisá-las e reconstruí-las. Isso exige um aprendizado da leitura crítica da prática, de análise fundamentada da situação para entendê-la e encontrar caminhos para reestruturá-la, tornando melhor (ANDRÉ, 2016, p. 32).

Nossa proposta para os bolsistas investigarem a prática pedagógica, a partir do estudo empírico de sua comunicação com os estudantes, em aulas de ciências, além da produção de biografias educativas, visou promover, durante a formação inicial, conhecimentos relevantes, em contextos reais de ensino e de aprendizagem. Nestes contextos, os licenciandos poderiam observar a si mesmos, buscando conhecer suas capacidades e necessidades formativas. Partilhando, deste modo, princípios formativos como autonomia, criatividade, parceria e sensibilidade, condições de desenvolvimento profissional (IMBERNON, 2012).

\section{Sujeitos, contexto e método no estudo da comunicação e na pesquisa da prática}

Assumir a prática pedagógica, durante a formação inicial, como campo de estudo, implicou o planejamento de condições de ensino e de pesquisa especiais, no âmbito do tema LC V , que é oferecido no quinto semestre do curso da LIECML e cuja ementa prevê o estudo da comunicação em aulas de ciências.

No planejamento do ensino foram previstas discussões teóricas sobre ensino e aprendizagem, prática pedagógica e comunicação em aula. Somado a isso, atividades orientadas para o planejamento, realização, registro e análise da aula. Frente ao propósito de realizar o estudo da comunicação em uma aula de ciências, outras atividades foram elaboradas com a intenção de ajudar os licenciandos a adotarem uma atitude ativa em relação à própria formação.

Assumimos, coletivamente, a pesquisa-ação colaboração que visa, "o desenvolvimento profissional do docente e a produção do conhecimento situacional e útil" (ESTEBAN, 2010, p.180). Nesse sentido, o planejamento da pesquisa considerou e valorizou a autonomia dos licenciandos.

A intenção de gerar novas compreensões sobre a aprendizagem em ciências e prática pedagógica orientada pela pesquisa, coexistem e se inter-relacionam de diferentes modos, expressando ênfases em momentos específicos do processo. No estudo da comunicação, a ênfase dada foi à discussão sobre a aprendizagem e o papel do professor. A pesquisa e reflexão sobre a prática focalizou a aprendizagem do licenciando, considerando a complexidade da atividade do professor pelas diferentes dimensões que a constituem.

Apresentamos, a seguir, as condições de ensino e de pesquisa geradas no âmbito do tema LC V, considerando que "não existem maneiras simples e óbvias de criar as condições que fomentem a pesquisa dos educadores nos programas de formação inicial e continuada de professores" (DINIZ-PEREIRA, 2011, p. 35). 


\section{O estudo da comunicação em aulas}

A ementa do tema LC $\vee$ reúne os seguintes assuntos "O estudo da comunicação em aulas de ciências. Relações entre alfabetização científica, alfabetização matemática e alfabetização em língua materna nos anos iniciais de escolarização". A carga-horária do tema é de 45h e foi realizado durante o primeiro semestre letivo de 2019.

Vinte e sete (27) licenciandos estavam matriculados, dentre estes, oito (8) eram bolsistas do PIBID. Não era a primeira experiencia da professora (primeira autora) com a realização desse tema. Desde a primeira vez que ministrou o tema, incluiu no programa o planejamento, realização e estudo da comunicação sobre uma aula de ciências.

Entre as atividades planejadas constavam assistir vídeos; ler, discutir e produzir sínteses de textos sobre o assunto; compartilhar ideias para o planejamento de uma aula; socializálas considerando o contexto de sua realização, o que incluía a comunicação com os estudantes da educação básica e o registro da aula. Além disso, no planejamento foram definidos momentos de orientação em grupo com o intuito de organizar, descrever, discutir e refletir sobre as informações produzidas.

As leituras, discussões e produções de sínteses dos textos foram orientadas por perguntas previamente fornecidas aos licenciandos. Ao mesmo tempo que as perguntas ajudavam a compreensão das leituras, também incentivavam a participação deles nos diálogos. A produção de sínteses compreensivas sobre os textos ocorreu ao longo de todo o trabalho com a turma. As respostas escritas eram lidas, avaliadas e devolvidas aos licenciandos, constituindo, gradativamente, um acervo pessoal que foi usado por eles, posteriormente, na produção escrita de seus relatos.

Para o estudo comunicativo da aula, onze (11) grupos de licenciandos foram formados, sendo que cada grupo reunia dois (2) ou três (3) integrantes. Eles planejaram, realizaram e registraram as aulas. As aulas ocorreram com turmas de estudantes do ensino fundamental das escolas públicas parceiras do Projeto PIBID - Subáreas de Ciências, Matemática e Linguagens do Ensino Fundamental do curso de LIECML/FEMCI e do Clube de Ciências da Universidade Federal do Pará (CCIUFPA).

Os licenciandos registraram as aulas em áudio e vídeo, usando seus smartfones. Os áudios da comunicação foram transcritos e, com a ajuda da professora, eles analisaram as interações com o foco nas condições de aprendizagem proporcionadas aos estudantes e no papel do professor.

Em grupo, os licenciandos produziram um relato sobre a aula, com uma descrição da mesma, incluindo os episódios comunicativos que cada grupo analisou. No encerramento do tema, este relato foi compartilhado com toda a turma.

Doze (12) licenciandos prosseguiram com o estudo e produziram relatos pessoais sobre a aprendizagem dos estudantes e o papel do professor. Dentre estes, sete (7) eram bolsistas PIBID. Assim, o processo de orientação continuou nos meses de julho e agosto de 2019. Onze (11) destes relatos foram submetidos ao Seminário do PIBID (Seminário PIBID/CML UFPA 2019). Todos os relatos submetidos foram aprovados. No evento, a apresentação deles foi seguida de um debate público entre os discentes e os avaliadores, que eram mestrandos e doutorandos do IEMCI. Esta experiência foi avaliada positivamente pelos licenciados bolsistas, que se comprometeram com a continuidade dos estudos. 


\section{Prática pedagógica: a produção de biografias educativas}

A investigação da prática pedagógica retomou a experiência vivida no estudo comunicativo, considerando a trajetória formativa mais ampla do licenciando no âmbito do curso e do Programa PIBID, com a produção de biografias educativas (JOSSO, 2010).

As biografias educativas são um recurso de formação que se produzem em um momento do processo formativo, e não tem a pretensão da globalidade de uma narração de vida do sujeito. Se orientam para o conhecimento sobre si mesmo e, de forma mais específica, sobre sua atuação como professor.

A interação com o grupo se prolongou até dezembro de 2019. Cinco (5) licenciandos bolsistas, chamados ficticiamente de Beth, Clara, Júlia, Paulo e João, investiram no prosseguimento do estudo com a produção das biografias educativas, orientados, inicialmente, pelas seguintes perguntas:

1. Como foi sua experiência de aprendizagem em ciências na Educação Básica?

2. Que ano ingressou na Licenciatura Integrada? Quais eram suas expectativas de aprendizagem no curso?

3. Que ano ingressou no PIBID?

4. Como foi a sua experiência inicial na escola parceira do PIBID?

5. Que você aprendeu com o planejamento, realização, registro e produção de relato da aula no tema Linguagem e conhecimento $\mathrm{V}$ ?

5.1 Sobre o que tratou a aula?

5.2 Como foi a participação das crianças?

5.3 O que você melhoraria na aula?

5.4 O que você considera que precisa aprender mais?

5.5 O que a iniciação à docência contribui com a tua formação?

6. Comente sobre o que há de comum e de diferente entre o que você viveu em teu processo de escolarização na educação básica e o que proporcionou às crianças das escolas participantes do PIBID?

7. Que professor você deseja ser e de que modo o PIBID te ajuda nesse projeto de formação?

A partir das respostas a estas perguntas, os bolsistas redigiram um texto. Discutimos os textos com eles e fizemos novas perguntas e esclarecimentos individuais via WhatsApp. As novas perguntas foram motivadas pelas situações singulares que emergiram do diálogo, gerando motivação para investigar mais. Analisando as interações com cada bolsista foi possível tecer uma compreensão sobre a trajetória formativa de cada licenciando e avaliar o impacto do tema.

Cada biografia educativa passou por uma revisão da escrita e foi usada como material de pesquisa em dois trabalhos, que foram aprovados no I Encontro Paraense de Licenciatura - I EPALIC. Também compuseram capítulos de livro que reuniram experiências de licenciandos participantes do programa PIBID. A comunicação é uma etapa importante da formação do professor pesquisador de sua prática, visto que ela também é uma exigência neste tipo de pesquisa (ANDRÉ, 2016).

No presente artigo, temos interesse de responder à pergunta: Que contribuições formativas o tema LC V possibilitou aos licenciandos bolsistas PIBID, a partir da pesquisa sobre a própria prática dos licenciandos com o estudo da comunicação em aula e a produção de biografias educativas? 
Assumimos a análise interpretativa-analítica inspirada na pesquisa narrativa (CONNELLY; CLANDININ, 2011). Esta análise pressupõe a definição de um foco para a leitura sistemática das informações produzidas, durante e após o processo de pesquisa. Definimos como linha narrativa as mudanças, os avanços e as projeções feitas pelos licenciandos bolsistas. Interpretamos o movimento formativo no diálogo teórico com os referenciais que subsidiam a pesquisa. Na figura 1 apresentamos uma síntese do que constituiu o estudo da comunicação em aulas de ciências e a pesquisa da prática.

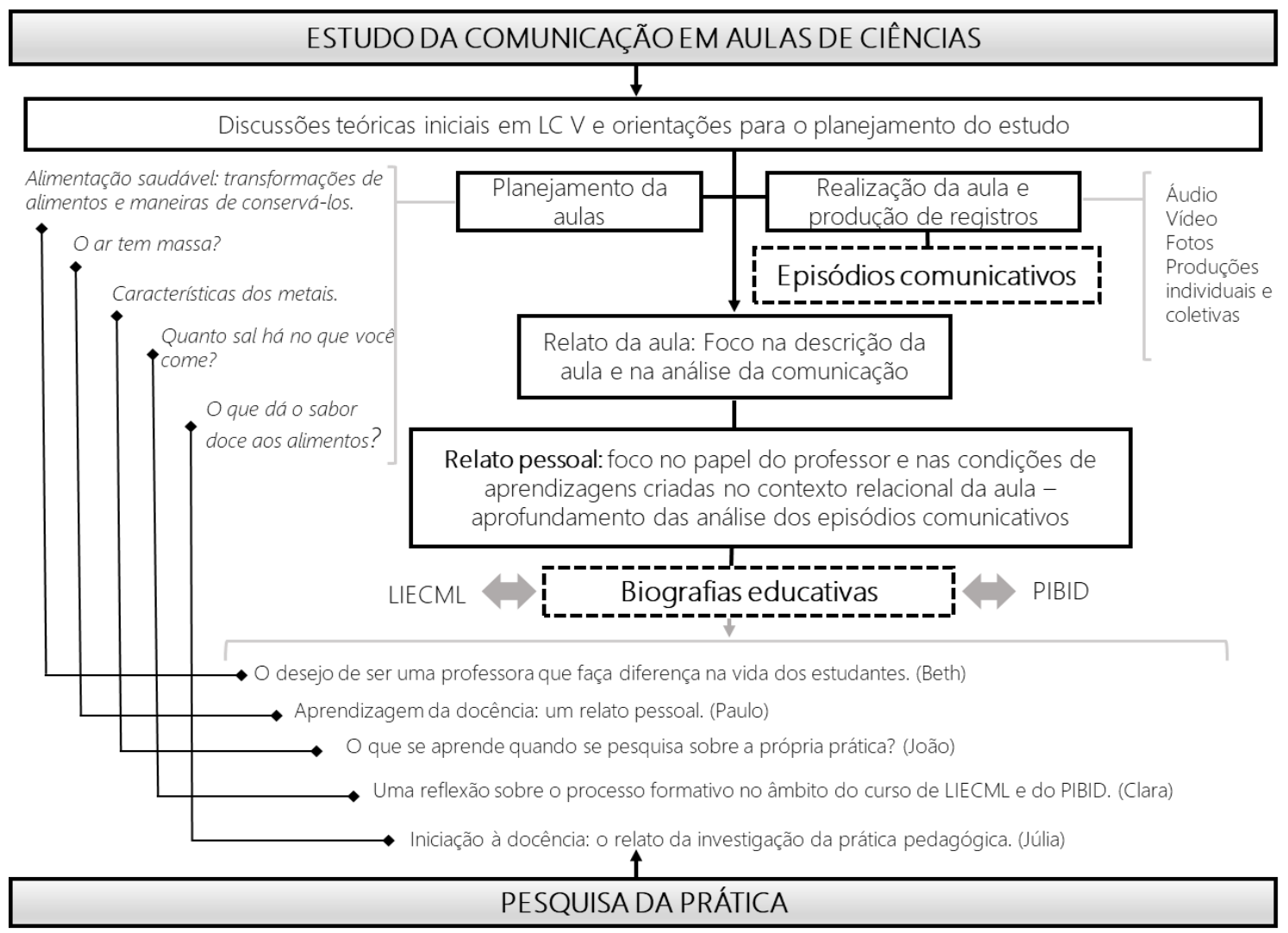

Figura 1 - Síntese do processo de pesquisa da prática

\section{Contribuições do tema Linguagem e Conhecimento V para a formação inicial de professores}

O maior desafio dos licenciandos foi articular as ideias de aprendizagem em ciências que discutimos e eram nossas referências, de forma coerente, no planejamento das aulas. Assim, na primeira socialização do planejamento ficou evidente a presença de atividades nas quais prevalecia a checagem dos conhecimentos prévios dos estudantes, sem explicitar os novos conhecimentos que poderiam ser ensinados. Além disso, as tarefas estavam voltadas para a reprodução de informações, portanto, numa visão de aprendizagem memorística. A percepção deste problema nos gerou angústia e motivou a ajudá-los. Na biografia educativa de Paulo ele relembra esse momento demonstrando que:

O tema Linguagem e Conhecimento $V$ teve um papel fundamental em nossa atuação na escola parceira do PIBID, pois nos fez refletir sobre o planejamento e a realização de uma aula no contexto da discussão teórica sobre a aprendizagem em ciências e o papel do professor nessa 
aprendizagem. As questões "Sobre o que tratará a aula? Em que eixo da BNCC o foco da aula se insere? Que conhecimentos a criança deve possuir em seu repertorio para participar da atividade? Por que é importante que as crianças aprendam sobre isso?" foram desafiadoras e de grande importância para orientar o planejamento da aula. (Biografia educativa, Paulo, 2019)

Foi necessário compartilhar experiências pessoais, realizando um exercício de articular a concepção de aprendizagem que estávamos compartilhando e as tarefas presentes nos planejamentos, incluindo, por exemplo, a participação dos estudantes em atividades que Ihes cobrassem uma produção, bem como a definição prévia de momentos de diálogos. Sobre isso, Altet, (2017, p.1203) assegura que:

Os professores que utilizam modalidades pedagógicas que dão a palavra ao aluno, que criam relações professor-aluno de confiança, encorajandoos na realização de tarefas, na resolução de problemas, orientando-os e os avaliando, e que têm expectativas mais altas em relação a todos os alunos são aqueles que produzem maior impacto sobre os resultados de aprendizagem.

Desta forma, avaliamos que foi fundamental compartilhar materiais didáticos diversificados e dar apoio aos licenciandos, discutindo sobre assuntos de ciências como algumas noções relativas à composição dos materiais, suas propriedades e características, reações, reciclagem, reutilização, transformação física e química, alimentação e nutrição. Tais noções compareceram nas intenções de ensino dos grupos e sentimos necessidade de problematizá-las para que eles pudessem produzir atividades, que fossem potencialmente mobilizadoras de novas relações dos estudantes com a linguagem científica.

Em três momentos diferentes do desenvolvimento do tema LC V eles apresentaram o planejamento e nós discutimos sobre as atividades. A cada socialização, além do aperfeiçoamento das atividades previstas, planejamos o estudo empírico, definindo como os registros seriam feitos e as informações produzidas. Cada integrante do grupo se responsabilizou e cuidou de um ou mais aspectos do que seria feito e registrado na aula, cabendo a todos, a comunicação com os estudantes.

A diversidade de objetivos presentes no planejamento dos grupos pode ser observada na Figura 2. Também incluímos na figura, os participantes de cada aula, bem como indicamos o título dos episódios que permitiram discutir sobre a situação comunicativa.

Na aula sobre Alimentação saudável: transformações de alimentos e maneiras de conservá-los, os estudantes tiveram a possibilidade de dar continuidade às discussões iniciadas com a professora regente por meio do texto poema "Mamão, Melancia, Tecido e Poesia" (SOMBRA, 2013). Os estudantes observaram diferentes alimentos (frutas e verduras), alguns em imagem, outros in natura, conservados por meio de processos diferentes como a desidratação e o uso de salmoura. Assim, por exemplo, observaram a banana em imagem e desidratada, reconheceram as diferenças na cor, na textura e no sabor. Observaram uva passas e desconheciam que a uva passa era uva desidratada. Os estudantes brincaram de adivinhar do modo como já tinham trabalhado com a professora regente, desta vez experimentando sucos de frutas. Provaram suco de uma mesma fruta natural sem açúcar, com açúcar e industrializado. Eles reconheceram somente as frutas cujo o suco continha 
açúcar ou eram industrializados. Os estudantes construíram desenhos sobre a aula e comentaram sobre eles para turma.

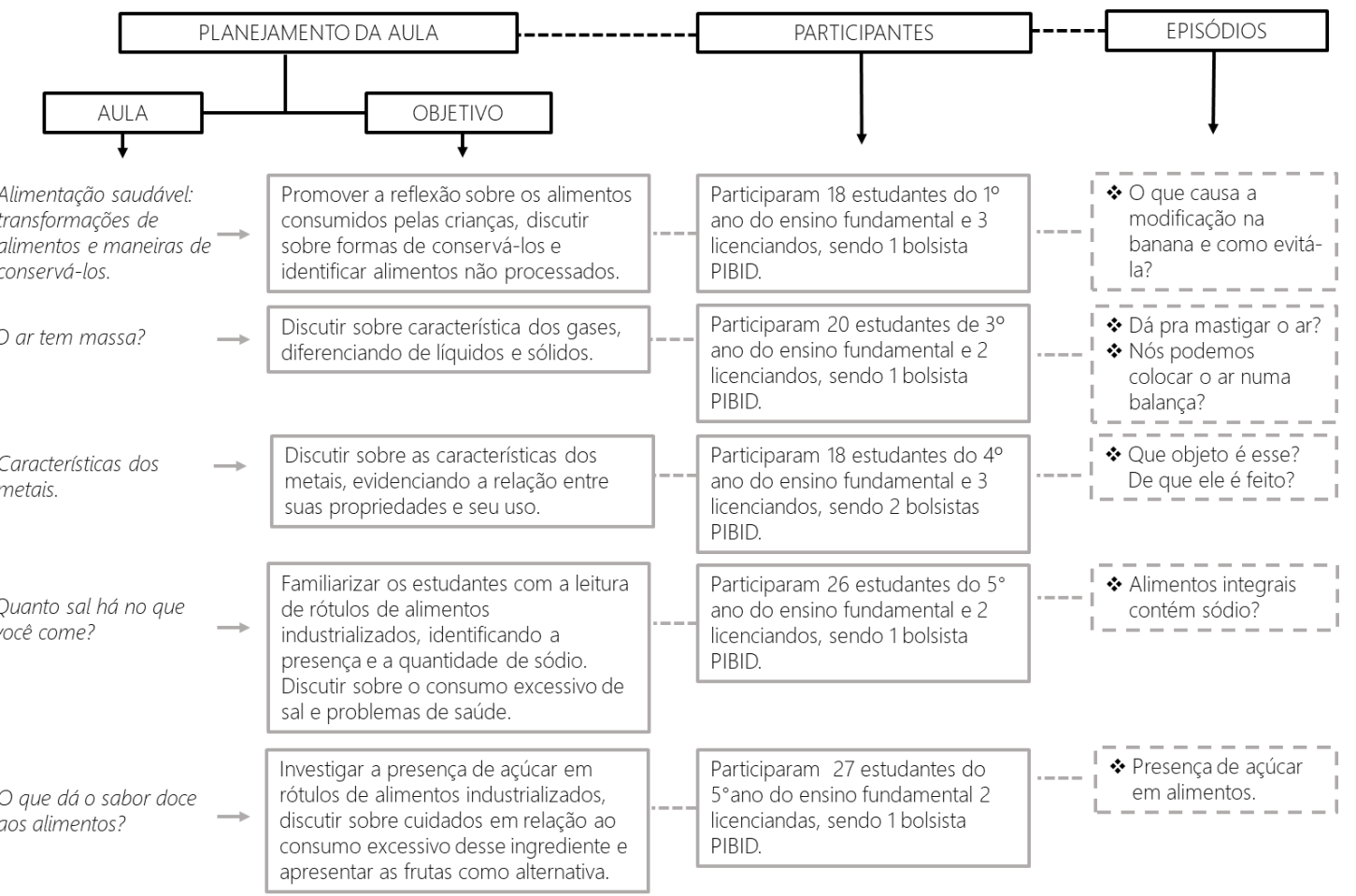

Figura 2 - Representação esquemática das aulas planejadas, dos participantes e episódios selecionados para análise.

$\mathrm{Na}$ aula $\mathrm{O}$ ar tem massa?, a intenção foi discutir sobre uma das características dos gases que é sua massa, uma vez que os estudantes só haviam estudado que era possível medir a massa da matéria no estado sólido e líquido. Os licenciandos usaram balanças feitas de canudinhos de plástico, barbantes e balões (bexigas). Propuseram aos estudantes, encher duas bexigas e fixar cada uma delas em uma das extremidades de um canudinho. Em seguida, solicitaram aos estudantes que avaliassem o porquê da bexiga tender para um lado e não para o outro ou assumir o equilíbrio. Tal situação permitiu produzir evidencias e negociar a ideia de que o ar possui massa. A atividade foi realizada em grupo e os estudantes produziram desenhos, pintaram e escreveram suas descrições e/ou explicações.

$\mathrm{Na}$ aula sobre Características dos metais, os licenciandos apresentaram aos estudantes alguns objetos feitos de metal e exploraram com eles as características de cada objeto. Em seguida, os licenciandos dialogaram, visando reunir as características comuns aos objetos apresentados para sistematizar as características gerais dos metais. Os estudantes desconheciam alguns objetos e insistiram, por exemplo, com uma corda de violão que, por ser flexível e estar na forma de fio, foi identificada como um fio feito de plástico. Os estudantes produziram desenhos e textos sobre a aula.

Tanto na aula Quanto sal há no que você come? quanto na aula O que dá o sabor doce aos alimentos? os licenciandos trabalharam na mesma turma, em dias diferentes, com a leitura de rótulos de alimentos industrializados, sendo que um grupo priorizou o estudo sobre a presença de sal nos alimentos e o outro o açúcar. Os rótulos de alimentos industrializados servem como meio de comunicação com o consumidor. Fazer escolhas 
saudáveis depende do quando compreendemos as informações presentes neles. Foi um propósito dos dois grupos tornar a linguagem acessível aos estudantes, sem pretender esgotar as possibilidades de interpretação.

No início, os dois grupos relataram que as crianças manifestaram dificuldades em lidar com tantas informações presentes nos rótulos de embalagens de alimentos, mas foram orientadas para a leitura, destacando características desse gênero textual. Somente após avaliarem que elas conseguiam identificar informações relevantes para os propósitos das atividades eles deram continuidade à interpretação das informações presentes nos rótulos.

Na aula Quanto sal há no que você come?, os licenciandos realizaram a discussão sobre a presença do sal nos alimentos, de forma integrada com conhecimentos matemáticos, a partir da leitura dos valores diários (VD), informações que constam nos rótulos no campo valor nutricional. Também agruparam os rótulos conforme a quantidade de sal, sinalizando com a cor verde, alimentos com zero VD de sódio; com a cor laranja, aqueles que no conjunto possuem um valor de VD de 1 a 4; cor vermelha, alimentos que possuem valores VD acima de 5. Os estudantes ficaram impressionados quando, ao agruparem os rótulos nas cores descritas anteriormente, identificaram que o macarrão instantâneo, alimento que consumiam frequentemente, possuía alto VD. Os licenciandos apresentaram alternativas para o consumo dos alimentos e responderam alguns questionamentos dos estudantes como: "Os alimentos integrais possuem sódio?". A turma produziu um quadro com as informações usando a lousa, os rótulos e as cores que sinalizavam a porcentagem de sódio nos alimentos.

A leitura do rótulo na aula O que dá o sabor doce aos alimentos? foi orientada para a identificação da presença de açúcar nos alimentos, que consta nos rótulos, no campo dos ingredientes. A partir das respostas a uma das perguntais iniciais dos licenciandos, foi possível perceber que os alimentos citados pelos estudantes continham como principal ingrediente o açúcar. O principal ingrediente em um alimento industrializado é o que está nele em maior quantidade, sendo que, essa informação pode ser verificada na lista de ingredientes, que deve constar nos rótulos das embalagens. Os estudantes produziram um cartaz informativo com alternativas de consumo de açúcar, usando figuras de frutas e vegetais.

Todas as atividades descritas anteriormente foram práticas pedagógicas intencionalmente elaboradas durante a realização do tema LC V, que se organizaram de diferentes formas na interação com os estudantes e expressaram modificação do repertório inicial de atividades que os licenciandos compartilharam na primeira socialização dos planejamentos. As práticas produzidas se diferenciavam da simples resolução de questionários e exercícios, procedimentos didáticos mais utilizados por professores que ensinam ciências nos anos iniciais (BUENO; FRANZOLIN, 2019).

Todos os licenciandos apresentaram relatos entusiasmados sobre as suas vivências, ainda que nestas também contivessem situações que causaram algum desconforto, como aconteceu na aula sobre o Ar tem massa? e Características dos metais.

$\mathrm{Na}$ aula sobre o Ar tem massa?, os licenciandos discutiram sobre a dificuldade de envolver os estudantes com o objetivo da atividade. Inclusive esse foi um aspecto que depois de manifestado pelo grupo, passou a ser debatido pelos outros grupos. Eles reconheceram também que o envolvimento dos estudantes com as atividades Ihes exigiu recursos pessoais e habilidades para incentivar a comunicação com os estudantes. A pergunta "Dá pra mastigar o ar?" foi uma das formas de incentivá-los a expressarem suas 
ideias. Ela foi feita por um licenciando bolsista, após ver um estudante mastigando chiclete e avaliando não ter mais alternativas para promover a participação da turma. Acolher as perguntas e incentivar a turma a expressar suas ideias provocou alterações no silêncio, antes predominante.

$\mathrm{Na}$ aula sobre as Característica dos metais, os licenciandos ficaram incomodados com as intervenções feitas pela professora regente da turma. Quando os licenciandos fizeram perguntas sobre o que eram os objetos e do que eles eram feitos, a professora ficou impaciente com o silêncio que tomou conta da aula logo no início. Ao tentar ajudar os licenciandos, buscando incentivar a participação da turma, a professora acabou oferecendo respostas e desencorajando os estudantes, fazendo críticas por não expressarem suas ideias. Contudo, os próprios licenciandos relataram que sentiram dificuldades ao conduzir o diálogo, já que em alguns momentos também ficaram tentados a agir da mesma maneira que a professora regente.

Sobre isso é relevante compreender que, por um lado, quando os estudantes tentam interpretar o sentido das intervenções do professor, podem surgir discursos duplos (sentidos diferentes para um mesmo termo), e discursos paralelos (deslocamento de sentido no discurso feito pelo professor sem que os estudantes o acompanhem). Por outro lado, quando o professor compreende as ideias dos estudantes, avalia que é melhor não compartilhar conhecimentos que julga estar fora do alcance deles ou antecipa as respostas, impedindo-os de formulá-las. Tais situações envolvem dinâmicas complexas no contexto de uma sequência de ensino e se desdobram como resultantes de processos que são influenciados, implicitamente, pelas representações mútuas entre os envolvidos (ASTOLFl; PETERFALVI; VÉRIN, 1998).

A ausência de comunicação em aula indica uma concepção de aprendizagem reprodutiva, que desconsidera a importância da participação e expressão das ideias dos estudantes. Transformar este cenário exige o desenvolvimento de recursos pessoais, aprendidos mediante o enfretamento de dificuldades, balizados por uma compreensão de aprendizagem que reconhece 0 papel ativo dos estudantes nesse processo. Tal compreensão também valoriza a atmosfera emocional criada pelos envolvidos na interação, de atividades que exijam produção da parte dos estudantes, enfim, de estratégias pedagógicas orientadas para a aprendizagem (TACCA, 2008). $O$ investimento dos licenciandos na interação com os participantes da aula parece ter sido influenciado pelas oportunidades formativas experimentadas no tema LC V e em outros temas do curso. João escreveu sobre isso:

Entendi que os modos de expressão se materializam e se encontram na sala de aula, e que não são iguais. E enquanto professor, preciso entender e aceitar meu papel de mediador, não só do conhecimento para o estudante, mas também de como essas vozes que circulam na sala de aula e expressam ideias e conceitos, ora se conflitam, ora se completam, e, sobretudo, permitem com que eu crie melhores condições de diálogo com os estudantes. Deste modo, penso que preciso criar mais estratégias para favorecer e incentivar o diálogo, repensar alguns questionamentos que fiz aos estudantes na ocasião da aula, para evitar ser tendencioso, induzindo os estudantes aos meus modos de ver as questões e situações, ao invés de serem livres para falar do modo que pensam (Biografia educativa, João, 2019). 
Foi possível notar o empenho dos licenciandos para proporcionar um clima agradável na interação com os estudantes. Isso se expressou nos momentos em que cada grupo compartilhou suas vivencias com a turma e nas situações comunicativas, pois eles se interessavam pelas perguntas e valorizavam as informações trazidas pelos estudantes.

Aprendi que a docência não é uma tarefa fácil, principalmente quando os estudantes são bem inquietos. [...] é preciso cautela para agir de maneira certa. [...] percebi a diversidade que há em sala de aula; de opiniões, ideias, e questionamentos dos alunos e que é preciso estar atento para que o ensino seja adequado a todos os estudantes (Relato pessoal, Clara, 2019).

Eles também relataram que, após o momento inicial, os estudantes se mostraram curiosos e engajados nas atividades. No encerramento e avaliação final das aulas, os estudantes geralmente perguntavam quando fariam de novo atividades parecidas com as que tinham feito naquele dia.

No processo de orientação da análise dos episódios, interagimos com cada grupo de licenciandos e acompanhamos o movimento comunicativo que se constituiu nas aulas que eles realizaram. Embora tivessem proporcionado uma situação comunicativa que valorizou as falas dos estudantes, acolheu vivencias e, na medida do possível, respondeu dúvidas e perguntas, dois aspectos relativos à aprendizagem da prática pedagógica dos licenciandos nos intrigaram. Primeiro, o fato de algumas situações não terem sido problematizadas. Segundo, quanto à estrutura da comunicação, que se mostrou presente nas sequencias de todos os grupos.

$\mathrm{Na}$ aula "O que dá o sabor doce aos alimentos?" ficou evidente que os estudantes entendiam que o sabor doce dos alimentos era decorrente, exclusivamente, do uso do açúcar comum. Eles avançaram na compreensão de que o leite e as frutas também eram fontes de açúcares, mas não de que o sabor doce poderia ser resultante da presença de outros ingredientes contidos nos alimentos. Ao percebermos que essa compreensão era também dos próprios licenciandos, investimos na discussão sobre o assunto. Primeiramente, oferecemos leituras. Em seguida, um questionamento via mensagem de Watsapp, para o grupo, no qual foi compartilhado um rótulo de um bolo diet que continha a informação "Sem açúcar" seguido do questionamento: Como ele pode ser doce se não tem açúcar? Por último, os licenciandos do grupo construíram juntos um quadro com grupos de substâncias que conferem sabor doce aos alimentos.

Alguns momentos não foram problematizados pelos licenciandos porque estes careciam de ferramentas simbólicas, que foram identificadas no processo de orientação da análise das situações comunicativas. Nesse sentido, os licenciandos tiveram oportunidade de avançar no conhecimento que possuíam e nós orientamos novas situações de ensino, envolvendo assuntos ligados aos conteúdos escolares, um dos focos do tema LC V e de fundamental importância para avançar nas análises. Assim, para as análises das situações comunicativas os grupos investiram no estudo de conteúdos relacionados às condições que afetam as transformações nos alimentos; a diferença entre massa e peso; materiais e objetos.

O processo de orientação e análise das situações comunicativas se mostrou um recurso para ensinar e aprender ciências e melhorar a prática pedagógica na medida que os licenciandos investiram na compreensão da linguagem científica que eles próprios usaram. Só com o conhecimento da linguagem científica e suas relações com os contextos sociais 
teremos mais condições de criar estratégias pedagógicas que impactem no processo de aprendizagem, tornando a linguagem da ciência acessível aos estudantes da educação básica. Sem esse comprometimento na formação inicial de professores para atuar nos anos iniciais e a disposição dos próprios licenciandos será muito difícil ampliar as possibilidades de aprendizagem em aulas de ciências.

A ausência de problematização das falas dos estudantes afetou as situações comunicativas geradas. A comunicação em aulas pode ser caracterizada como dialogal ou dialógica (ASTOLFI; PETERFALVI; VÉRIN, 1998). Dialogal descreve a forma de troca e o dialógico a sua estrutura. É dialogal por não se constituir de monólogos magistrais, mas do cruzamento de interlocuções distintas. Ainda que a forma dialogal permita interlocuções distintas, a estrutura da comunicação pode ser um monólogo. Neste caso, o que se manifesta na sequência de ensino é uma progressão temática única, e não dois discursos que se confrontam. Portanto, há participação, mas não há debate. Os episódios com progressão temática única foram característicos das situações comunicativas analisadas pelos licenciandos.

Beth escreveu sobre o registro e a reflexão gerada com a análise:

Registrar aguça nosso olhar de pesquisador e nos faz dar importância a coisas que passariam despercebidas. Na fase do relato pude recapitular alguns pontos, principalmente ouvindo os áudios com as falas das crianças. Relatar foi como observar nossa própria prática, com outro olhar, apurar erros e acertos e refletir sobre toda experiência (Beth, Relato pessoal, 2019).

Precisamos oferecer condições formativas que incentivem os licenciandos a problematizarem as falas dos estudantes, provocando mudança na estrutura da comunicação em aula. Isso nos exige lidar com situações problema que afetam a vida das pessoas e para as quais as respostas são obtidas em um processo de construção contínua. Requer lidar com a dimensão social do conhecimento da ciência, algo que precisamos buscar intencionalmente.

\section{Considerações finais}

Realizamos o presente estudo, articulando ensino e pesquisa no ensino superior e, ao mesmo tempo, incentivando, durante a formação inicial, uma atividade de pesquisa dos licenciandos sobre sua prática. A continuidade da formação e da pesquisa envolveu cinco (5) licenciandos bolsistas PIBID e exigiu a criação de novos espaços de discussão e reflexão, que tornou possível responder nossa questão sobre a contribuição do tema LC $\vee$ para a formação inicial de professores.

Compreendemos que, ao realizarem o estudo da comunicação em aulas de ciências, os licenciandos tiveram oportunidades de avaliar suas concepções de aprendizagem, de debatê-las e modificá-las. Também avançaram na direção de representações mais sintonizadas com a perspectiva formativa do curso, ao expressarem compreensões sobre as dimensões formativas que constituem a prática pedagógica.

Deste modo, compreendemos que o planejamento da aula e a análise das situações comunicativas foram significativos em termos de mudanças percebidas nas ações e 
reflexões dos licenciandos. Esses avanços foram confirmados por eles na construção de suas biografias educativas.

As produções das biografias educativas também confrontaram as experiencias vividas no âmbito da formação inicial com suas memórias das aulas de ciências na educação básica. Incentivaram os licenciandos a fazerem um exercício de aproximação e diferenciação destas memórias com as atividades que ofereceram às crianças na aula de ciências da escola parceira. Também favoreceram pensar e avaliar as ações atuais, projetando novas aprendizagens e a melhoria da prática pedagógica. Tais reflexões não estão descoladas do projeto de formação que os licenciandos concebem, atualmente, para suas vidas e que compartilham na formação inicial.

Assim, a pesquisa sobre a prática possibilitou aos licenciandos compreenderem processos de ensino-aprendizagem, ao realizarem uma prática diferenciada, na qual ensinaram um tema relevante, valorizando a comunicação. Além de relacionar teoria e prática, os licenciandos tiveram a oportunidade de refletir sobre a experiência entre outras experiências de sua história de formação e explicitar novos interesses relacionados à teoria e à prática pedagógica.

A socialização dos estudos, tanto entre os licenciandos quanto com a comunidade universitária, repercutiu também sobre nosso ofício de formadores de professores. Acreditamos que a intencionalidade com que foram propostas as atividades formativas e a análise crítica dessas experiências se aproximam da ideia de autorenovação das universidades, defendida por Imbernón (2012). Nesse sentido, o autor destaca que a pesquisa sobre a docência da matéria é uma possibilidade que temos de lidar com os desafios que se impõem ao cumprimento de nossas funções, sendo geradora de desenvolvimento profissional. Entretanto, ele adverte que esse trabalho é coletivo e envolve a Universidade como um todo, já que o clima institucional de trabalho impacta na prática pedagógica do professor. Foi com esse espírito que constituímos nossa parceria de trabalho e temos projetado no ensino do tema Linguagem e Conhecimento a pesquisa sobre nossa prática de formação inicial.

\section{Referências}

ALTET, M. A observação das práticas de ensino efetivas em sala de aula: pesquisa e formação. Cadernos de Pesquisa, v. 47, 2017, p.1196-1223. Disponível em: http://www.scielo.br/pdf/cp/v47n166/fr_1980-5314-cp-47-166-1196.pdf. Acesso em: 9 fev. 2019.

ALVES J. M.; PARENTE A. G. L. Linguagem e conhecimento, tema da formação inicial na Licenciatura Integrada em Ciências, Matemática e Linguagem. Revista REAMEC, v. 8, n. 1, p.249-267. Disponível em:

http://periodicoscientificos.ufmt.br/ojs/index.php/reamec/article/view/9861/pdf. Acesso em: 18 abr. 2020

ANDRÉ, A. Formar o professor pesquisador para um novo desenvolvimento profissional. In: ANDRÉ, M. (Org.). Práticas inovadoras na formação de professores. Campinas, SP: Papirus, 2016, p.17-34.

ASTOLFI, Jean-Pierre; PETERFALVI, Brigitte; VÉRIN, Anne. Como as crianças aprendem ciências. Lisboa: Instituto Piaget, 1998. 
BUENO, K. C.; FRANZOLIN, F. A utilização de procedimentos didáticos nas aulas de ciências Naturais dos anos iniciais do ensino fundamental. Revista Electrónica de Enseñanza de las Ciencias, v. 18, 2019, p.387-412. Disponível em:

http://reec.uvigo.es/volumenes/volumen18/REEC_18_2_5_ex1444.pdf. Acesso em: 19 dez. 2019.

CACHAPUZ, A.; PRAIA, J.; JORGE, M. Da educação em ciência às orientações para o ensino das ciências: um repensar epistemológico. Ciência e Educação, v. 10, 2004, p.363-381. Disponível em: http://www.scielo.br/pdf/ciedu/v10n3/05.pdf. Acesso em: 20 mai. 2012.

CONNELLY, F. Michael; CLANDININ, D. Jean. Pesquisa narrativa: Experiência e História em Pesquisa Qualitativa. Trad. Grupo de Pesquisa narrativa e Educação de Professores ILEEL/UFU, Uberlândia: EDUFU, 2011.

DINIZ-PEREIRA, J. E. A pesquisa dos educadores como estratégia para a construção de modelos críticos de formação docente. In: DINIZ-PEREIRA, J. E.; ZEICHNER, K. M. (Orgs.). A pesquisa na formação e no trabalho docente. Belo Horizonte: Autêntica Editora, 2011, p.11-37.

DRIVER, R., ASOKO, H., LEACH, J., MORTIMER, E. F., SCOTT, P. Construindo conhecimento cientifico na sala de aula. Química Nova na Escola, n. 9, 1999, p.31-40. Disponível em: http://qnesc.sbq.org.br/online/qnesc09/aluno.pdf. Acesso em: 20 mai. 2012.

EMMEL, R.; PANSERA-DE-ARAÚJO, M. C. Cenários reflexivos na prática de ensino da formação inicial de professores em Ciências Biológicas. Amazônia: Revista de Educação em Ciências e Matemática, v. 13, 2017. p.181-200. Disponível em: https://periodicos.ufpa.br/index.php/revistaamazonia/article/view/5078/4616. Acesso em: 18 mai. 2020.

ESTEBAN, M. Paz Sandín. Pesquisa qualitativa em educação: fundamentos e tradições. Porto Alegre: AMGH, 2010.

FAGUNDES, T. B. Os conceitos de professor pesquisador e professor reflexivo: perspectivas do trabalho docente. Revista Brasileira de Educação. v. 21, 2016, p.281-298. Disponível em: http://www.scielo.br/pdf/rbedu/v21n65/1413-2478-rbedu-21-65-0281.pdf. Acesso 9 fev. 2019

FERNANDES, D. G.; MIGUEL, J. R. Contribuições de uma aula de campo para a aprendizagem de conhecimentos científicos nos anos iniciais do ensino fundamental. Amazônia: Revista de Educação em Ciências e Matemática. v. 13, 2017. p.64-77. Disponível em: https://www.periodicos.ufpa.br/index.php/revistaamazonia/article/view/5253/4614. Acesso em: 18 mai. 2020.

GATTI, Bernardete Angelina; BARRETTO, Elba Siqueira de Sá; ANDRÉ, Marli Eliza Dalmazo Afonso de; ALMEIDA, André Patrícia Cristina Albieri de. Professores do Brasil: novos cenários de formação. Brasília: UNESCO, 2019.

GONZÁLEZ REY, F. L. A imaginação como produção subjetiva: as ideias e os modelos da produção intelectual. In: MARTÍNEZ, A.M. e ÁLVAREZ (Orgs.) O sujeito que aprende: diálogo entre a psicanálise e o enfoque histórico-cultural. Brasília: Liber Livro, 2014, p.35-61.

IMBERNÓN, Francisco. Inovar o ensino e a aprendizagem na Universidade. Tradução Silvana Cobucci Leite. São Paulo: Cortez, 2012. 
JOSSO, M. C. Da formação do sujeito...Ao sujeito da formação. In: NÓVOA, A.; FINGER, M. (Orgs.). O método (auto) biográfico e a formação. Natal: EDUFRN; São Paulo: PAULUS, 2010, p.59-79.

MITJÁNS MARTINEZ, Albertina; GONZÁLEZ REY, Fernando. Psicologia, Educação e Aprendizagem Escolar: avançando na contribuição da leitura cultural-histórica. São Paulo: Cortez Editora, 2017.

SOMBRA, Fábio. Mamão, melancia, tecido e poesia. São Paulo: Ed. Moderna, 2013.

STENHOUSE, Lawrence. La investigación como base de la enseñanza. Ged. Madri: Ediciones Morata, 1987.

TACCA, M. C. V. R. Estratégias pedagógicas: conceitualização e desdobramentos com foco nas relações professor aluno. In: TACCA, M. C. V. R. Aprendizagem e trabalho pedagógico. Campinas: Alínea, 2008, p. 45-68.

VYGOTSKY, Lev Semyonovich. A formação social da mente. São Paulo: Martins Fontes, 1984. VYGOTSKY, Lev Semyonovich. Pensamento e linguagem. São Paulo: Martins Fontes, 1987. 